\title{
Total Diet Studies as a Tool for Ensuring Food Safety
}

\author{
Joon-Goo Lee, Sheen-Hee Kim, Hae-Jung Kim and Hae-Jung Yoon \\ Food Contaminants Division, Department of Food Safety Evaluation, National Institute of Food and Drug Safety Evaluation, \\ Ministry of Food and Drug Safety, Cheongju, Korea
}

(Received August 22, 2015; Revised September 10, 2015; Accepted September 21, 2015)

\begin{abstract}
With the diversification and internationalization of the food industry and the increased focus on health from a majority of consumers, food safety policies are being implemented based on scientific evidence. Risk analysis represents the most useful scientific approach for making food safety decisions. Total diet study (TDS) is often used as a risk assessment tool to evaluate exposure to hazardous elements. Many countries perform TDSs to screen for chemicals in foods and analyze exposure trends to hazardous elements. TDSs differ from traditional food monitoring in two major aspects: chemicals are analyzed in food in the form in which it will be consumed and it is cost-effective in analyzing composite samples after processing multiple ingredients together. In Korea, TDSs have been conducted to estimate dietary intakes of heavy metals, pesticides, mycotoxins, persistent organic pollutants, and processing contaminants. TDSs need to be carried out periodically to ensure food safety.
\end{abstract}

Key words: Risk analysis, Total diet study, Dietary exposure, Risk assessment

\section{INTRODUCTION}

As the food industry becomes increasingly globalized, consumers' concerns over food safety also increase. Consumers have begun to opt for health-promoting foods. With the increasing food-related scams in global food markets, each country has implemented food safety policies to protect its citizens and its food industries. The melamine milk scandal of 2008 astonished the world with the death of six infants caused by the consumption of adulterated milk as well as kidney and urinary problems in 250,000 children in China. The total estimated cost incurred to the Chinese healthcare system was 58 million Euros (1). In 2008, numerous Koreans who worried about contracting mad cow disease from beef imported from the US protested for over three months. These huge and unprecedented demonstrations had shaken the nation and influenced political deci-

Correspondence to: Hae Jung Yoon, Food Contaminants Division, Department of Food Safety Evaluation, National Institute of Food and Drug Safety Evaluation, Ministry of Food and Drug Safety, Osong-eup, Heungdeok-gu, Cheongju-si, Chungcheongbuk-do 363-700, Korea

E-mail: hjyoon@korea.kr

This is an Open-Access article distributed under the terms of the Creative Commons Attribution Non-Commercial License (http:// creativecommons.org/licenses/by-nc/3.0) which permits unrestricted non-commercial use, distribution, and reproduction in any medium, provided the original work is properly cited. sion-making (2). Countries are prioritizing food safety because food safety has gained greater importance in people's lives. Consumers request more scientific evidence supporting the safety of the food. With food safety policies becoming more restrictive, conflicts between importers and exporters in the food trade emerge with regard to food safety regulations (3). To date, TDS is one of the most efficient tools for ensuring food safety; risk managers can make decisions based on the background information of chemicals in food provided by TDSs. The purpose of this paper is to review the current status of TDS implementation.

\section{TDS FOR RISK ANALYSIS}

Risk analysis, including risk management, risk assessment, and risk communication, has been developed to estimate and control risk as well as communicate risk information. Risk analysis is used to develop safety standards and represents an essential part in the food safety emergency response. Risk assessment is a key input in risk analysis and comprises four elements: hazard identification, hazard characterization, exposure assessment, and risk characterization. Hazard identification aims to identify the biological, chemical, and physical properties potentially harmful to human health. Hazard characterization aims at evaluating, based on experimental data, any harmful effect according to hazard exposure levels. Exposure assessment determines the intake of hazardous products via food. Risk 
characterization consists of estimating the probability of occurrence and severity of hazards (4). To estimate the magnitude of risk to human health that may be caused by a food component, TDSs have been widely used to assess the dietary exposure, in terms of chemical concentration, of the component in a particular food product while considering the safety threshold of the component in human body (5).

\section{DIFFERENCES BETWEEN TDS AND FOOD MONITORING}

Food monitoring investigates chemical concentrations in individual foods. An official agency examines the chemical levels in food for compliance with the regulatory guidelines in specific food items. On the other hand, TDSs are conducted for monitoring chemicals in consumed foods, and require additional food processing in the kitchen to prepare samples. Therefore, TDSs are able to obtain more real-

Table 1. List of priority chemicals at the $4^{\text {th }}$ international TDS workshop

\begin{tabular}{ll}
\hline \hline Group & Contaminant \\
\hline Pesticides & Aldrin \\
& DDT (total) \\
o,p'-DDD \\
p,p'-DDD \\
o,p'-DDE \\
p,p'-DDE \\
o,p'-DDT \\
p,p'-DDT \\
Dieldrin \\
Endosulfan (total) \\
Endosulfan \\
Endosulfan epoxide \\
Endrin (total) \\
Endrin \\
Endrin ketone \\
Hexachlorocyclohexane (HCH) (total) \\
Alpha-HCH \\
Beta-HCH \\
Gamma-HCH \\
Hexachlorobenzene \\
Heptachlor (total) \\
Heptachlor \\
Heptachlor-epoxide \\
Diazinon \\
Fenitrothion \\
Malathion \\
Parathion \\
Methyl parathion \\
Dithiocarbamates (total) (as CS2 equiv.) \\
Cadmium \\
Lead \\
Methylmercury \\
Arsenic (inorganic) \\
\\
Heavy metals
\end{tabular}

Table 1. Continued

\begin{tabular}{|c|c|}
\hline Group & Contaminant \\
\hline Industrial chemicals & $\begin{array}{l}\text { Polychlorinated Biphenyls (PCBs) } \\
\text { (total expressed in WHO TEFs) } \\
\text { Marker PCBs } \\
\text { IUPAC No. } 28 \\
\text { IUPAC No. } 52 \\
\text { IUPAC No. } 101 \\
\text { IUPAC No. } 138 \\
\text { IUPAC No. } 153 \\
\text { IUPAC No. } 180 \\
\text { Polychlorinated Dibenzodioxins } \\
\text { (PCDDs) (total expressed in WHO } \\
\text { TEFs) } \\
\text { 2,3,7,8-TCDD } \\
\text { 1,2,3,7,8-PeCDD } \\
\text { 1,2,3,6,7,8-HxCDD } \\
\text { 1,2,3,4,7,8-HxCDD } \\
\text { 1,2,3,7,8,9-HxCDD } \\
\text { 1,2,3,4,6,7,8-HpCDD } \\
\text { 1,2,3,4,6,7,8,9-OCDD } \\
\text { Polychlorinated Dibenzofurans } \\
\text { (PCDFs) (total expressed in WHO TEFs) } \\
\text { 2,3,7,8-TCDF } \\
\text { 1,2,3,7,8-PeCDF } \\
\text { 2,3,4,7,8-PeCDF } \\
\text { 1,2,3,6,7,8-HxCDF } \\
\text { 1,2,3,4,7,8-HxCDF } \\
\text { 1,2,3,7,8,9-HxCDF } \\
\text { 2,3,4,6,7,8-HxCDF } \\
\text { 1,2,3,4,6,7,8-HpCDF } \\
\text { 1,2,3,4,7,8,9-HpCDF } \\
\text { 1,2,3,4,6,7,8,9-OCDF } \\
\text { Polychlorinated Biphenyls (PCBs) } \\
\text { (total expressed in WHO TEFs) } \\
\text { Mono-ortho PCBs } \\
\text { IUPAC No. } 105 \\
\text { IUPAC No. } 114 \\
\text { IUPAC No. } 118 \\
\text { IUPAC No. } 123 \\
\text { IUPAC No. } 156 \\
\text { IUPAC No. } 157 \\
\text { IUPAC No. } 167 \\
\text { IUPAC No. } 189 \\
\text { Non-ortho PCBs } \\
\text { IUPAC No. } 77 \\
\text { IUPAC No. } 81 \\
\text { IUPAC No. } 126 \\
\text { IUPAC No. } 169\end{array}$ \\
\hline Mycotoxins & $\begin{array}{l}\text { Aflatoxins (total) } \\
\text { Aflatoxin B1 } \\
\text { Aflatoxin B2 } \\
\text { Aflatoxin G1 } \\
\text { Aflatoxin G2 } \\
\text { Patulin } \\
\text { Fumonisin B1 } \\
\text { Ochratoxin A }\end{array}$ \\
\hline
\end{tabular}


istic average concentration data and are useful in the assessment of exposure to processing contaminants, such as acrylamide and polycyclic aromatic hydrocarbons, which are occurred at the processing stages of manufacture. TDSs are also cost-effective because composite samples are analyzed $(6,7)$. However, chemicals may be diluted in a pooled sample in which highly contaminated foods are mixed with several less contaminated ones. Therefore, the analytical methods used in TDSs need to be of higher sensitivity compared with those used for food compliance monitoring (8). Furthermore, quality assurance (QA) during sample preparation should be emphasized to avoid contamination and loss of chemicals (9).

\section{THE GLOBAL STATUTES OF TDSS}

In 1961, the first TDSs were initiated in the US to determine the levels of radioactive Sr-90 in foods and beverages prepared for consumption by washing, removing inedible parts, and cooking (10). TDSs gained recognition at the Joint Food and Agriculture Organization (FAO)/World Health Organization (WHO) Meeting on Pesticide Resi- dues in 1967 (11). The European Food Safety Authority, the FAO, and WHO recommended a harmonized TDS method (9). Furthermore, WHO convened five international TDS workshops to encourage countries to implement reliable and harmonized TDSs (12-15). The ongoing TDSs in different countries were presented and developments in TDS methodologies were discussed in workshops. A list of priority chemicals was recommended at the first workshop and updated at the fourth workshop (Table 1). In particular, at the third workshop, a one-week training course was prepared that could be followed by the countries planning to incorporate TDSs The most recent workshop was convened in Seoul, Korea in 2015 by the Ministry of Food and Drug Safety (MFDS), the Korean Health Industry Development Institute, and the WHO Regional Office for the Western Pacific. The participants of the workshop adopted the eleven recommendations (Table 2).

\section{NATIONAL TDSs}

Among country-specific TDSs (Table 3) (16), the US Food and Drug Administration (FDA) has conducted TDSs

Table 2. Recommendations adopted at the $5^{\text {th }}$ international workshop on TDS

1) All countries are encouraged to conduct total diet studies to assess the safety and nutritional quality of diet of their population.

2) Countries may want to expand their TDS to address gaps in their current studies as well as emerging food safety and nutritional issues.

3) All countries, particularly low-income countries, are encouraged to explore opportunities for capacity building as well as both shortand long-term financial and technical support to conduct TDS. This should include regional and/or international support through such agencies and instruments as the World Trade Organization's Standards and Trade Development Facility (STDF), the World Bank's Global Food Safety Partnership, the European Union's TDS-Exposure Project, the Asia-Pacific Economic Cooperation's Food Safety Cooperation Forum, Association of Southeast Asian Nations' Food Safety Network, the Joint International Atomic Energy Agency/Food and Agriculture Organization of the United Nations Division of Nuclear Techniques in Food and Agriculture, the International Life Sciences Institute, and WHO Collaborating Centers for Food Contamination Monitoring.

4) Countries should utilize existing training courses, such as the European Union-supported Summer School for TDS and those sponsored by national governments, as well as resources, such as the Dutch National Institute for Health and the Environment's software for exposure assessment "Monte Carlo Risk Assessment" as well as hands-on experience and other transfers of TDS expertise among countries.

5) Countries are encouraged to use a harmonized and regional approach, whenever possible, when conducting TDS.

6) Countries should improve and/or develop detailed, transparent and regionally harmonized food classification and description systems that should be the basis for conducting their TDS.

7) In planning of their TDS, countries are encouraged to refer to the criteria for developing lists of priority chemicals and nutrients and to consider the suggested lists of TDS chemicals developed by the workshop. Countries may also wish to refer to the list of typical limits of determination of analytical methods needed to achieve measured results for various chemicals, which was prepared by the workshop.

8) Countries are encouraged to actively utilize the GEMS/Food Databases as well as the GEMS/Food Cluster Diets (in the absence of food consumption data) and contribute to GEMS/Food Databases using the established reporting format.

9) Based on best practice in risk communication, all countries are strongly encouraged to communicate TDS results in a transparent, timely, and easy-to-understand manner to all stakeholders.

10) WHO Collaborating Centers for Food Contamination Monitoring are encouraged to strengthen their role in supporting lowincome countries in the conduct of TDS through capacity building, resource mobilization, and provision of technical expertise.

11) Future international TDS workshops should be organized periodically to share experiences and best practices in TDS. It is also recommended that future TDS training courses be held with a particular focus on building TDS capacity in low-income countries. Workshops and training courses may be jointly sponsored by WHO, WHO Collaboration Centers, and other international and regional organizations and national agencies with experience in conducting TDS. 
Table 3. Comparison of TDSs among countries

\begin{tabular}{|c|c|c|c|c|c|c|c|c|}
\hline & USA & UK & Australia & France & Canada & Korea & Japan & China \\
\hline $\begin{array}{c}\text { Food } \\
\text { consumption } \\
\text { data }\end{array}$ & $\begin{array}{c}\text { CSFU } \\
\text { (NHANES) }\end{array}$ & NDNS & NNS & INCA & NNCS & $\begin{array}{c}\text { KNHANES } \\
\text { (NNS before } \\
\text { 2000) }\end{array}$ & $\begin{array}{l}\text { National } \\
\text { nutrition } \\
\text { survey }\end{array}$ & $\begin{array}{c}\text { CNNS } \\
\text { CNNHS } \\
\text { (after 2002) }\end{array}$ \\
\hline Composite & No & Yes & No & Yes/No & No & $\begin{array}{c}\text { No } \\
\text { (Yes in 2000) }\end{array}$ & Yes & Yes/No \\
\hline Food list & 280 & 119 & 65 & 338 & 210 & 358 & 130 & 240 \\
\hline Mapping & Yes & No & Yes & No & No & Yes/No & No & No \\
\hline Analytes & $\begin{array}{l}\text { Heavy metals, } \\
\text { Minerals, } \\
\text { Perchlorate, } \\
\text { Radionuclides } \\
\text { POPs } \\
\text { Processing } \\
\text { contaminants }\end{array}$ & $\begin{array}{l}\text { Acrylamide, } \\
\text { Dioxins, } \\
\text { Endocrine } \\
\text { disruptors, } \\
\text { Heavy metals, } \\
\text { Minerals, } \\
\text { PAHs, } \\
\text { Radionuclides }\end{array}$ & $\begin{array}{l}\text { Dioxins, } \\
\text { Endocrine } \\
\text { disruptors, } \\
\text { Food additives, } \\
\text { Heavy metals, } \\
\text { Minerals, } \\
\text { Mycotoxins, } \\
\text { Pesticides }\end{array}$ & $\begin{array}{c}\text { Heavy } \\
\text { metals, } \\
\text { Minerals, } \\
\text { Mycotoxins }\end{array}$ & $\begin{array}{l}\text { Dioxins, } \\
\text { Endocrine } \\
\text { disruptors, } \\
\text { Heavy metals, } \\
\text { Minerals, } \\
\text { Nitrosamines, } \\
\text { Pesticides, } \\
\text { Radionuclides }\end{array}$ & $\begin{array}{c}\text { Heavy } \\
\text { metals, } \\
\text { Mycotoxins, } \\
\text { Pesticide, } \\
\text { Processing } \\
\text { contaminants, } \\
\text { PCBs }\end{array}$ & $\begin{array}{c}\text { Dioxins, } \\
\text { Endocrine } \\
\text { disruptors, } \\
\text { Heavy metals, } \\
\text { Minerals, } \\
\text { Pesticides, } \\
\text { Radionuclides }\end{array}$ & $\begin{array}{c}\text { POPs, } \\
\text { Heavy metals, } \\
\text { Pesticides, } \\
\text { Mycotoxins, } \\
\text { Minerals, } \\
\text { Lipids }\end{array}$ \\
\hline
\end{tabular}

to analyze approximately 350 different components, including pesticide residues, radionuclides, persistent organic pollutants (POPs), and processing contaminants, in 280 foods. (17). In Australia, TDSs have been conducted on 65 foods to assess the exposure to POPs, heavy metals, minerals, radionuclides, and endocrine disruptors (18). In Canada, TDSs have been performed on 210 foods to access different chemicals; the most recent one involved checking for bisphenol A $(19,20)$. In France, TDSs have been conducted on 338 foods; the firstbeing from 2000 to 2004 to estimate the dietary exposure to mycotoxins, minerals, and trace elements (21). The second TDS, conducted between 2006 and 2010 , extended the exposure data to 445 substances, including additives, plant protection product residues, and processing contaminants (22). TDSs have been annually conducted in UK on 65 foods to check for hazardous chem- icals, such as heavy metals, pesticides, and dioxins, since $1966(23)$.

In Korea, TDSs have been conducted since 1990s for heavy metals, pesticides, mycotoxins, and processing contaminants. The food list has been expanded, and the number of chemicals tested has increased since the Korean TDS master plan was established in 2011. The number of representative foods increased from 114 in 2004 to 186 in 2011. In the same period, the number of chemical groups assessed increased from three to five, incorporating POPs and processing contaminants (24). A 3-year TDS program is currently collecting data for 23 processing contaminants from 2013 to 2016. A representative group of 358 foods is combined with 33 cooking methods. Twelve laboratories participated in this program to perform the chemical analysis (Fig. 1). UK, France, Japan, China, and Korea analyzed
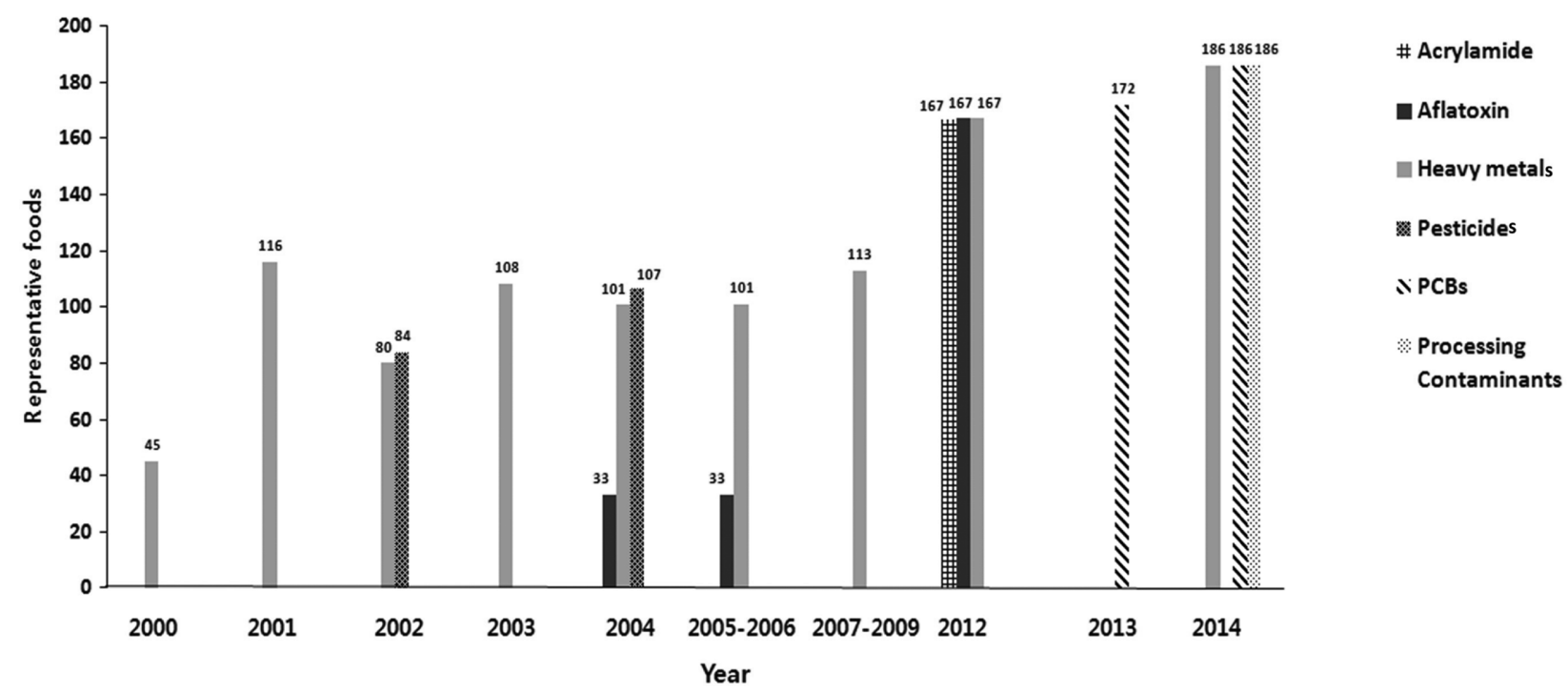

Fig. 1. Representative foods and targeted chemicals increase in Korean TDSs since 2000. 
composite samples, while USA, Australia, and Korea used a mapping approach.

\section{TDS USAGES IN FOOD SAFETY}

TDSs can be used for several aspects of food safety. When used as a screening tool, TDS can identify food groups and hazardous chemicals that require detailed food monitoring (9). TDSs provide temporal trends in hazards exposure, allowing risk managers to evaluate the effectiveness of food safety policies. For example, in the US, the FDA TDS has identified trends in the level of lead in the food supply and importantly, the decrease in lead exposure following the implementation of food safety policies (25). TDSs are also used to detect changes in the levels of processing contaminants associated with specific cooking methods, allowing regulatory authorities to make recommendations on cooking methods most likely to reduce chemical exposure. The Korean TDSs conducted in 2012 showed that the cooking method adopted influenced the acrylamide levels in the final product. Acrylamides were found to be below detection limits in raw, boiled, or baked potatoes but acrylamide was detected in stir-fried potatoes leading the study to conclude that boiling and baking are better methods than stir-frying to avoid exposure to acrylamide (26).

\section{CONCLUSIONS}

This paper has reviewed the purposes of TDSs, the differences between TDS and food monitoring, and TDS applications. TDS is not only a cost-effective tool but also a realistic tool for risk assessment of chemicals in foods because foods are analyzed in the form they are consumed and composited. TDSs are also useful for screening chemicals and identifying the trends of chemical exposure due to intake. Many countries, including Korea, have implemented TDSs to ensure food safety. The international organizations such as WHO, FAO and EFSA have tried to harmonize the TDS methodology. Although some challenges for TDSs, such as chemical priority, risk communication, and quality control, still remain, it is anticipated to gain importance in regulating the food safety; experts should endeavor to improve the quality of scientific evidence brought forward by TDSs.

\section{REFERENCES}

1. Pei, X., Tandon, A., Alldrick, A., Giorgi, L., Huang, W. and Yang, R. (2011) The China melamine milk scandal and its implications for food safety regulation. Food Policy, 36, 412420.

2. Lee, S.O., Kim, S.J. and Wainwright, J. (2010) Mad cow militancy: neoliberal hegemony and social resistance in South Korea. Political Geogr., 29, 359-369.
3. Hooker, N.H. (1999) Food safety regulation and trade in food products. Food Policy, 24, 653-668.

4. World Health Organization, Food and Agriculture Organization of the United Nations. (2006) Food safety risk analysis: a guide for national food safety authorities. FAO Food Nutr. Pap., 87, 1-10.

5. Conacher, H.B.S., Graham, R.A. and Graham, N.G.F. (1989) The health protection branch total diet program: an overview. Can. Inst. Food Sci. Technol. J., 22, 322-326.

6. International programme on chemical safety (IPCS). (2009) Principles and methods for the risk assessment of chemicals in food/dietary exposure assessment of chemicals in food. World Health Organization (WHO) Press, Geneva, pp. 10-14.

7. Boorman, J.L., Baines, J., Hambrdge, T.L. and Abbey, J.L. (2013) Total Diet Study-What They Are and Why They Are important/Total Diet Study. Springer, New York, pp. 179-190.

8. Moy, G.G. (2013) Total Diet Study-What They Are and Why They Are important/Total Diet Study. Springer, New York, pp. 3-10.

9. European Food Safety Authority (EFSA), Food and Agriculture Organization (FAO) and World Health Organization (WHO). (2011) Towards a harmonized Total Diet Study approach: a guidance document. EFSA J., 9, 2450.

10. Pennington, J.A. and Gunderson, E.L. (1987) History of the Food and Drug Administration's total diet study--1961 to 1987. J. Assoc. Off. Anal. Chem., 70, 772-782.

11. World Health Organization. (1968) Pesticide residues: report of the 1967 joint meeting of the FAO working party and the WHO expert committee, Rome, Italy, FAO and WHO, Geneva. Available from: http://apps.who.int/iris/bitstream/ 10665/40693/1/WHO_TRS_391.pdf?ua=1.

12. World Health Organization. (1999) GEMS/FOOD total diet studies: report of a joint USFDA/WHO international workshop on Total Diet Studies in cooperation with the Pan American health organization, Kansas City, USA, World Health Organization. Available from: ftp://ftp.ksph.kz/ Chemistry_Food\%20Safety/TotalDietStudies/Diet.pdf.

13. World Health Organization. (2002) GEMS/FOOD total diet studies: report of the $2^{\text {nd }}$ international workshop on Total Diet Studies, Brisbane, Australia, World Health Organization. Available from: http://whqlibdoc.who.int/hq/2002/9241562196.pdf.

14. World Health Organization. (2004) GEMS/FOOD total diet studies: report of the $3^{\text {rd }}$ international workshop on Total Diet Studies, Paris, France, World Health Organization. Available from: http://www.who.int/foodsafety/publications/chem/TDS Paris_en.pdf.

15. World Health Organization. (2006) GEMS/FOOD total diet studies: report of the $4^{\text {th }}$ international workshop on Total Diet Studies, Beijing, China, World Health Organization. Available from: http://www.gencat.cat/salut/acsa/html/ca/dir3576/ tds_beijing_2006_en.pdf.

16. Kim, C.I., Koh, E.M., Shin, H.H., Yon, M.Y., Nam, E.J., Lee, Y.N., Kim, D.H. and Lee, J.Y. (2011) Planning of Total Diet Study for hazardous materials. The $R \& D$ Annual Report of KFDA, 15, 193-194.

17. Food and Drug Administration (FDA). (2014) Total Diet Study: elements results summary statistics-market baskets 2006 through 2011. US Food and Drug Administration. Available from: http://www. fda.gov/downloads/food...totaldiet- 
study/ucm184301.pdf.

18. Food Standards Australia New Zealand (FSANZ). (2014) $24^{\text {th }}$ Australian Total Diet Study, Food standards Australia New Zealand. Available from: http://www.foodstandards.gov.au/ publications/Documents/1778-FSANZ_AustDietStudy-web.pdf.

19. Smith, D.C. (1970) Pesticide residues in the total diet in Canada. Pestic. Sci., 2, 92-95.

20. Cao, X.L., Perez-Locas, C., Dufresne, G., Clement, G., Popovic, S., Beraldin, F., Dabeka, R.W. and Feeley, M. (2011) Concentrations of bisphenol A in the composite food samples from the 2008 Canadian total diet study in Quebec City and dietary intake estimates. Food Addit. Contam. Part A, 28, 791-798.

21. Leblanc, J.C., Guérin, T., Noël, L., Calamassi-Tran, G., Volatier, J.L. and Verger, P. (2005) Dietary exposure estimates of 18 elements from the $1^{\text {st }}$ French Total Diet Study. Food Addit. Contam., 22, 624-641.

22. Arnich, N., Sirot, V., Rivière, G., Jean, J., Noël, L., Guérin, T. and Leblanc, J.C. (2012) Dietary exposure to trace elements and health risk assessment in the $2^{\text {nd }}$ French Total Diet Study. Food Chem. Toxicol., 50, 2432-2449.

23. Rose, M., Baxter, M., Brereton, N. and Baskaran, C. (2010) Dietary exposure to metals and other elements in the 2006 UK Total Diet Study and some trends over the last 30 years. Food Addit. Contam. Part A, 27, 1380-1404.

24. Ysart, G., Miller, P., Crews, H., Robb, R., Baxter, M., De L'argy, C., Lofthouse, S., Sarget, C. and Harrison, N. (1999) Dietary exposure estimates of 30 elements from the UK Total Diet Study. Food Addit. Contam., 16, 391-403.

25. Bolger, P.M., Yess, N.J., Gunderson, E.L., Troxell, T.C. and Carrington, C.D. (1996) Identification and reduction of sources of dietary lead in the United States. Food Addit. Contam., 13, 53-60.

26. Korea Health Industry Development Institute. (2011) Korean Total Diet Study-Mycotoxins, Heavy Metals, Acrylamide. The R\&D Report of Korean Ministry of Food and Drug Safety. 